\title{
Characterizing post-disaster reconstruction training methods and learning styles
}

\author{
Alexander Zerio (i), Aaron Opdyke (i) and Amy Javernick-Will (i) \\ Department of Civil, Environmental and Architectural Engineering, University of Colorado Boulder, Boulder, CO 80309, USA
}

\begin{abstract}
Large disasters damage or destroy infrastructure that is then reconstructed through programmes that train community members in construction techniques that reduce future risks. Despite the number of post-disaster reconstruction programmes implemented, there is a dearth of research on education and training in post-disaster contexts. To address this gap, we applied a mixed methods approach based upon experiential learning theory (ELT) to three shelter programmes administered in Eastern Samar, Philippines following Typhoon Haiyan. First, we characterize postdisaster training programmes based on learning modes and then, compared this to the learning styles of community members. To assess learning modes of training programmes, we analysed qualitative data from interview accounts of community members and aid organizations; and, to delineate community member's learning style preferences, we analysed quantitative data from survey questionnaires. Findings show that aid organizations administered training largely in lecture format, aligning with the reflective observation mode of ELT, but lacked diversity in formats represented in other poles of ELT. Moreover, analysis revealed that community members tended to grasp new information in accordance with the concrete experimentation mode, then preferred transforming newly acquired knowledge via the reflective observation mode. The lecture-based training predominately administered by aid organizations partially aligned with community learning preferences, but fell short in cultivating other forms of knowledge acquisition known to enhance long-term learning.
\end{abstract}

ARTICLE HISTORY

Received 1 August 2016

Accepted 2 November 2016

\section{KEYWORDS}

Training; disasters; experiential learning theory

\section{Introduction}

Communities, recovering from a disaster event, tend to rebuild using the same risk-prone designs, leading to new construction that is only marginally safer than pre-disaster conditions (Olshansky, 2009). While many factors contribute to reconstruction, including financing, time, and skill; this research focuses on one component of recovery - skill development through training. A focus on measuring the impact of involving the communities in recovery vs. measuring the output of recovery activities (e.g. number of structures built) has gained increased importance for aid organizations (Lawther, 2009). Consequently, to use training as a means of community involvement not only empowers locals (Davidson et al. 2007), but adds additional benefits, such as psychosocial recovery (Sullivan, 2003). Further studies (e.g. Barakat, 2003; Thwala, 2005; Barenstein, 2006; Fallahi, 2007) demonstrate multiple advantages of community participation in post-disaster recovery, such as cost savings, quality control, increasing construction capacity, and preserving the cultural heritage of affected communities. However, there is a lack of studies that unpack and analyse training programmes administered in post-disaster environments. Yet, better understanding and characterization of these programmes is critical, as training has the potential to improve recovery outcomes and reduce future risks within communities impacted by disasters.

As disasters and their corresponding effects continue to escalate (Guha-Sapir et al. 2015), the United Nations (UN) has championed efforts to reduce disaster impacts by improving the resilience of both the built environment and social systems. This charge crystalized with the declaration that the 1990s were to be the International Decade for Natural Disaster Reduction. The work derived from this programme manifested with the UN adoption of the International Strategy for Disaster Reduction (UNISDR). One of its earliest priorities, set forth in the 2005 Hyogo Framework for Action, was to 'use knowledge, innovation and education to build a culture of safety and resilience at all levels' (ISDR, 2007, p. 9). UNISDR's newest guiding document, the Sendai Framework for Disaster Risk Reduction, also includes a priority that 'enhances disaster preparedness for effective response and to "Build Back Better" in recovery, rehabilitation and reconstruction' (UNISDR, 2015, p. 21).

The charge to build back better, widely adopted by international aid organizations, requires the global 
populous to be trained in order to achieve these goals. And, derivatively, as disasters continue to increase, it becomes even more critical to improve recovery practices by training local community members in construction skillsets. There is no single technique or methodology currently used to train a diverse community comprehensively. However, within educational theories on learning styles, we know that learners must receive information in a variety of ways to enhance not only the acquisition and retention of knowledge, but also its understanding and application (Prince and Felder, 2006). Knowing this, we assessed and categorized three construction training programmes employed in the wake of Typhoon Haiyan through the lens of experiential learning theory (ELT). This theory defines learning as the process whereby knowledge is created through the transformation of experience. Knowledge results from the combination of grasping and transforming experience' (Kolb, 1984, p. 38). When grasping new information, ELT postulates learning occurs on a continuum with two learning modes or poles: concrete experience and abstract conceptualization. Once grasped, learners transform this experience on a separate continuum with two additional modes: active experimentation and reflective observation.

In order to improve training, we must first understand and unpack the types of post-disaster construction training programmes employed and determine the learning modes that they accommodate. Therefore, we seek to better understand post-disaster construction training programmes by collecting and analysing the learning modes employed within training programmes implemented by aid organizations following Typhoon Haiyan. We ask:

RQ1: What learning modes are accommodated by postdisaster construction training programmes?

The application of learning styles outside of traditional classroom education, such as post-disaster training sites, is sparse. However, a study of learning styles of community members receiving training in post-disaster programmes, compared to the learning modes implemented in training programmes in these settings, has the opportunity to improve the theoretical application of education research and the practical implementation of post-disaster training programmes. Further, based on educational research in learning styles, we know that individuals develop preferences for how they receive information and knowledge. A better understanding of community member preferences, and the alignment of these preferences with the training methods, may enhance post-disaster reconstruction programmes in resource-limited contexts. Doing so requires assessing both the learning modes used by aid organizations to administer training programmes and the learning styles of community members. Therefore, our second research question asks:

RQ2: What are the learning styles of community members trained in post-disaster construction?

\section{Background}

The UN doctrine over the last three decades has expressed the desire to reduce disaster effects on the built environment. One manner in which to achieve this goal is by educating communities to 'Build Back Better'. Many post-disaster shelter reconstruction programmes have a training element to educate builders and community members on design and construction techniques that enable safer shelter. In 2010, the World Bank published a holistic reference guide on the process of reconstruction after natural disasters and dedicated an entire chapter on the requirements for reconstruction training programmes (Jha, 2010). This chapter included recommendations regarding staffing, governance, structure, policy considerations, and content. It advocates for varied training methods comprising of lecture format, model building, and practical demonstrations.

However, much of the shelter reconstruction literature (e.g. Asharose et al. 2015; Thayaparan et al. 2015; Tuladhar et al. 2015) focuses on training deficiencies, but does not further unpack training programmes to understand the specified goals of the programmes, analyse the intended target audience, and categorize the training methods. To address this, our research employs ELT and Kolb's Learning Style Inventory (LSI) to assess training programmes conducted by aid organizations to Filipino community members after Typhoon Haiyan.

\section{Experiential learning theory}

As Dewey (1938, p. 7) noted, ' ... there is an intimate and necessary relation between the process of actual experience and education'. Grounded in work by Dewey (1938), Lewin (1951), and Piaget (1973), Kolb (1984) developed ELT, which is an approach to education and learning based in philosophy, social psychology, and cognitive psychology. Kolb envisioned a 'framework for examining and strengthening the critical linkages among education, work, and personal development' (1984, p. 4). The links that he describes attempt to bridge the gap between the 'abstract ideas of academia into the concrete practical realities' of everyday life (Kolb, 1984, p. 4). ELT (1984) is based upon six distinct propositions: 
(1) Learning is best conceived as a process, not in terms of outcomes (p. 26).

(2) Learning is a continuous process grounded in experience (p. 27).

(3) The process of learning requires the resolution of conflicts between dialectically opposed modes of adaptation to the world (p. 29).

(4) Learning is a holistic process of adaptation (p. 29).

(5) Learning involves transactions between the person and the environment (p. 35).

(6) Learning is the process of creating knowledge (p. 35).

In Kolb's theory for experiential learning, he submits that learning occurs within a 'four-stage cycle involving four adaptive learning modes - concrete experience, reflective observation, abstract conceptualization, and active experimentation' (Kolb, 1984, p. 40). These four modes, or stages, are defined below:

- The concrete experience (CE) mode characterizes a person's emphasis on feeling and analysis of the present reality, as opposed to thinking and a concern over the theories and concepts that apply.

- The abstract conceptualization (AC) mode, opposite of $\mathrm{CE}$, centres on thinking rather than feeling. This mode focuses on logic and concepts that downplay artistic influences.

- The reflective observation (RO) mode concentrates on understanding a situation's meaning through observation. This mode is less concerned with the pragmatic application of ideas, but rather understanding the true underlying concepts that govern.

- The active experimentation (AE) mode, opposite of RO, places practical application of ideas over the need to understand their meaning. Therefore, this mode cares about what works at the present moment and not necessarily the fundamental concept behind it.

The first of Kolb's major assumptions is that a learner progresses through the four modes in a clockwise manner that accentuates the adaptive and integrative process of learning by experience. While learners may prefer a particular mode, they transform learning into knowing by navigating through all four modes.

\section{Learning styles}

Kolb indicates that the relationship between abstract conceptualization vs. concrete experience (AC-CE) and active experimentation vs. reflective observation (AE$\mathrm{RO})$ are 'two distinct dimensions, each representing two dialectically opposed adaptive orientations' (Kolb, 1984, p. 41). This is Kolb's second major assumption, effectively stating that learners must choose a greater partiality towards one mode or the other. To explain further and depicted in Figure 1, the AC-CE dimension consists of prehension, whereas the $\mathrm{AE}-\mathrm{RO}$ dimension is that of transformation. Prehension is the process of either grasping experience by tangible qualities, called

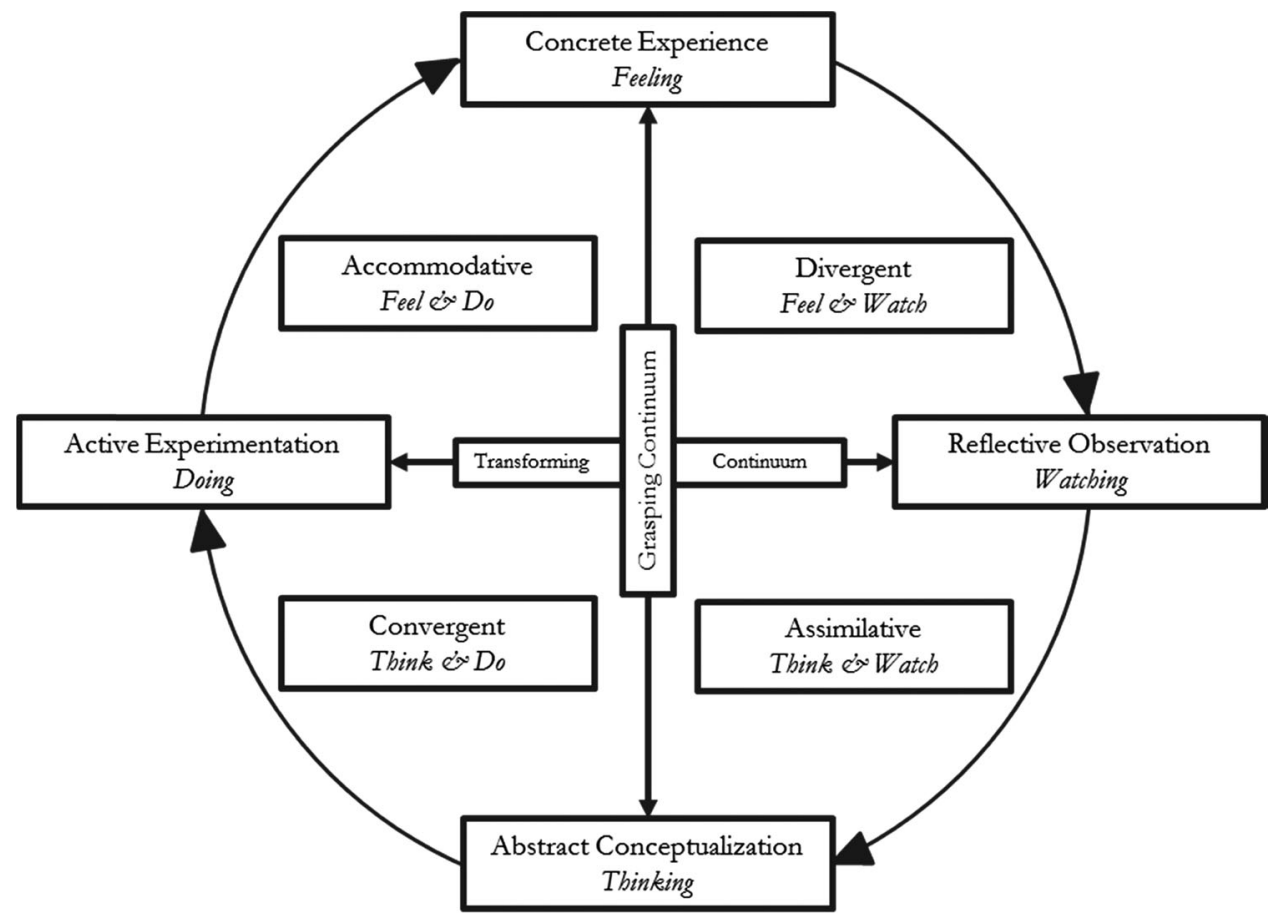

Figure 1. Kolb's cycle of experiential learning. 
apprehension (CE) or conceptual interpretation, named comprehension (AC). Transformation is then the processing of this grasped experience, focused on contrary methods of internal reflection, called intention (RO) or through active handling, called extension (AE).

Although Kolb describes that learning best occurs when the student travels through all four stages of the learning styles, he accepts the basic human tenant of gravitating to programmed tendencies that are influenced by five different levels: personality, educational specialization, professional career, current job role, and adaptive competencies (Kolb and Kolb, 2005). Based on the observational research of Hudson (1966), Torrealba (1972), and Grochow (1973), Kolb thus characterizes four learning styles - convergent, assimilative, divergent, and accommodative - as shown in the quadrants in Figure 1.

The convergent learner is dominant between the abstract conceptualization and active experimentation modes. The convergent knowledge seeker's prehensive tendency is toward comprehension (AC) and transforms it through extension (AE). He or she performs well when solving problems with only one answer and prefers to address technical tasks while avoiding social concerns. Oppositely, the divergent learning style relies on concrete experimentation and reflective observation. The divergent style grasps knowledge through apprehension (CE) and transforms it through intention (RO). This group tends to be problem solvers due to their imaginative nature and reliance on generating alternative perspectives to a problem. They thrive in interpersonal brainstorming sessions. Those that assimilate knowledge do so through abstract conceptualism and reflective observation. The assimilative style grasps knowledge through comprehension (AC) and transforms it with intention (RO). These individuals excel at development of theoretical models by integrating seemingly disconnected pieces of information into a single thought. Lastly, and opposite to assimilators, are the accommodative learners who use concrete experience and active experimentation. The accommodative style uses apprehension to take in experience and transforms it via extension (AE). They are prone to the 'trial-and-error' method, are action based, and heavily reliant on personal interaction. When the presented facts do not fit the proposed theory, they disregard the theory and adapt to the facts.

\section{Learning style inventory}

While ELT professes a varied exposure to the four modes and styles, Kolb observed that individuals would gradually condition themselves to prefer a particular learning style. Thus, he developed the LSI to determine this preference. Kolb constructed LSI to adhere to a few basic tenets. The first is that LSI should resemble an actual learning experience for the user, thereby forcing the survey respondent to address their partiality between concrete vs. abstract prehension and reflective vs. active transformation. Secondly, Kolb made LSI a self-assessment, convinced that people's description of themselves would better represent their true self than a performance test would show. Lastly, he wanted a valid, simple, yet candid assessment that could provide virtually instant feedback.

The LSI has undergone several revisions since its creation in 1969, but we employed Version 3.1, published in 2005, for our research. This version has undergone a multitude of different studies (e.g. Ruble and Stout, 1990, 1991; Veres et al. 1991; Kayes, 2005) confirming internal consistency reliability, which is a robust indication of validity. On top of which, its mainstream use in measuring learning styles (Kolb and Kolb, 2005) and for its applicability across national and cultural context (Barmeyer, 2004; Yamazaki, 2005; Joy and Kolb, 2009) offer further justification for its selection. For each of the 12 questions within the LSI, the respondent ranks four statements that complete a sentence stem (e.g. 'I learn best when') on an ipsative scale of 1-4 in a manner reflecting their preferences. The results include scores that highlight the emphasis that respondents place on each of the four modes (CE, $\mathrm{RO}, \mathrm{AC}$, and $\mathrm{AE}$ ), and a derivative score that indicates their preference on the dimensional scales (AC-CE, AE-RO).

One component from the body of education theory seeks to understand the impact that an individual's learning style imparts on knowledge prehension and transformation. The study of learning styles is typically confined to academic contexts, such as curriculum development and cross-cultural learning. We apply the same theory of learning style to a post-disaster reconstruction setting. Using Kolb's ELT as a lens, this paper identifies communities' preferred learning styles and analyses training programmes according to ELT's learning modes.

\section{Methodology}

This research aimed to characterize residential post-disaster construction training programmes and identify community members' preferred learning styles. To accomplish this, we selected a mixed method research design. Mixed methods research is defined as

the type of research in which a researcher or team of researchers combines elements of qualitative and quantitative research approaches (e.g. use of qualitative and 
quantitative viewpoints, data collection, analysis, inference techniques) for the broad purposes of breadth and depth of understanding and corroboration.

(Johnson et al. 2007, p. 123)

The narrative data adds context and meaning to the numerical data derived from the Kolb LSI survey. Conversely, the LSI data corroborate and add precision to the interview accounts. In the end, the two sets of data become mutually beneficial. We conducted this research within three communities in Eastern Samar, Philippines following Typhoon Haiyan.

\section{Research context}

In November 2013, Typhoon Haiyan decimated a large swath of the central Philippines. All told, the storm killed over 6000 people, injured almost 29000 , destroyed or damaged 1.1 million homes and cost over $\$ 12.9$ billion in economic impacts (NEDA, 2013; Del Rosario, 2014). By February 2014, over 65 nations and private donors contributed close to $\$ 663$ million (USD) in relief aid in areas ranging from logistics, shelter, water, sanitation, and economic recovery (Lum and Margesson, 2014). Numerous international organizations assisted the Philippines throughout early post-disaster response and recovery, with many of these aid organizations helping with shelter reconstruction projects. To provide context on the national culture of the Philippines, we turn to Hofstede (2001), who states that there are cultural dimensions that distinguish countries from one another. Examining the Philippines through Hofstede's cultural dimension scores, we find that the Philippines scored relatively high on 'Power Distance', thus revealing a hierarchical society and low on 'Individualism', suggesting the Philippines' affinity toward collectivism, notably centred around the family unit; and low on 'LongTerm Orientation', suggesting they are normative in their thinking, closely adhering to established traditions, taking a cautious view of any proposed social change, and focus on achieving quick results.

\section{Community selection}

We collected and analysed data within three communities from Eastern Samar - Cantahay, Cogon, and Sulangan. We selected these communities because they had similar damage levels from the typhoon and were comparable in size and socio-economic demographics, but they had different implementing organizations, which resulted in the implementation of different postdisaster recovery training strategies. Additionally, the population size and shelter reconstruction plan,
Table 1. Number of shelters.

\begin{tabular}{lccc}
\hline & & \multicolumn{2}{c}{ Shelters } \\
\cline { 3 - 4 } Barangay & Population (2010) & Planned & Completed \\
\hline Cantahay & 1118 & 169 & 105 \\
Cogon & 1146 & 132 & 133 \\
Sulangan & 3597 & 300 & 100 \\
\hline
\end{tabular}

summarized in Table 1, are notably similar as to draw comparisons across communities.

We selected a community (or barangay - the lowest political level within the Philippines) as the unit of analysis for our research since a regional breakdown was too broad and individual households too specific. A community includes the active participation of aid organizations' leadership and members, along with local stakeholders categorized as government officials, shelter beneficiaries, or skilled labourers.

\section{Data collection}

Within the three communities identified for analysis, data collection occurred in two distinct phases. In the first phase, the research team's second author conducted semi-structured interviews with project stakeholders (e.g. community members and aid organizations) that focused on identifying training methods employed at different recovery stages. We employed a snowball sampling technique that incorporated consultation from aid organizations working on the ground to achieve diversity in opinions and involvement. Respondents were selected from the communities who both actively participated in a construction training programme and those that did not participate. Interviews were conducted in the native language of Waray with the help of a translator. These interviews were then translated and transcribed into English. Within the three communities, 42 interviews were conducted -6 with respondents from three separate aid organizations and 38 with local stakeholders.

In the second phase of research, we collected additional quantitative data from within the selected communities. A local research assistant, familiar with the region and a native Waray speaker, administered a written survey to community members that collected basic demographic information along with administering Kolb's LSI. The research assistant translated the survey responses, conveyed in the native Waray dialect, into English for our analysis. We wanted to ensure a representative sample of participants, including both males and females, and obtain responses from individuals who had participated in a structured training programme. Of the 118 total responses, 47\% (56 
respondents) were male, 53\% (62) were female, and 34\% (40) noted they had participated in a structured training programme.

\section{Data analysis}

\section{Qualitative analysis}

We imported the interview transcripts into NVivo coding software to conduct content analysis. We blended our approach by including deductive and inductive coding that generated relevant themes for further analysis. Our initial coding structure used 'top-down' or deductive information derived from ELT and were revised through 'bottom-up' or inductive refinement that incorporated any emergent categories (Fereday and Muir-Cochrane, 2006). Overall, our analysis initially unpacked the training methods employed by aid organizations, then subsequently categorized these methods according to ELT's learning modes.

In order to ascertain accuracy, we continually reviewed the data for coding and categorized various aspects according to the established themes (Creswell, 2013). An undergraduate researcher assisted by coding the data independently. The research team met on an iterative basis to verify the coding dictionary and discuss emergent themes. Using NVivo software, we ran a coding comparison across pertinent nodes (e.g. ELT mode) and sources (e.g. community members). The inter-rater reliability score, in the form of Cohen's Kappa coefficient, averaged across interviews was 0.68 , suggesting sufficient agreement. Kappa scores in excess of 0.4 are considered acceptable, whereas scores over 0.8 are considered excellent (Munoz and Bangdiwala, 1997).

The final codebook contained several categories, but for the scope of this paper, we will focus on the following major themes: training methods, training objectives, and community perception. Training methods stemmed from our deductive coding, which categorizes the employed training methods to the learning modes of ELT. For example, when an interviewee said 'Yes, there were lectures done, like on the measurements, and they were taught how to use the carpenter's meter. That was important, how to use the meter', we coded it as lecture format, which, in turn, deductively relates in ELT terms to reflective observation. Training objectives and community perception emerged through the process as prominent themes. As an example for one these themes, one shelter beneficiary stated, 'I have learned some new things in this construction, like making the rings [rebar stirrups] on the steel bars. They are using a different way from what we used to do here.' This statement fits into the Community Perception theme, which we then coded inductively as a positive sentiment.

\section{Quantitative analysis}

To understand the learning style preferences of community members, we analysed and recorded each respondent's answers to Kolb's LSI. To review, the LSI is a 12-question survey that provided statements of learning methods where respondents rate their agreement or disagreement according to their preferences. The completed LSI produces a measurement of six ELT variables that includes four primary scores that are tied to the learning modes (CE, RO, AC, AE) and two combination scores that measure the preference on the two continuums (AE-RO, AC-CE). For example, when a respondent ranked a statement that was most preferred, it translated into a score of 4 and conversely a score of 1 meant it was the respondent's least preferred statement. Each of the 12 questions correlate to a learning mode and the resulting summation of statement rankings produced its score. With the four primary scores calculated, we derived the combination score by subtracting the two dialectic modes on the two separate continuums (AE-RO, AC$\mathrm{CE}$ ). The combination scores for an individual were then plotted.

The next step was to aggregate the individual plots into our unit of analysis: the community. This aggregation incorporated two measures: the mean plot based on the two continuums (AE-RO, AC-CE) and the standard deviation from the mean for the community at large. We derived the mean by plotting the average $\mathrm{AE}-\mathrm{RO}$ score on the $x$-axis and the AC-CE average on the $y$-axis. We visually represented the variation of a community's scores by calculating the standard deviation along each continuum, scaled it to the Learning Style Type Grid, and then assigned these values to the dimension of an oval, whose centre was the mean plot. The oval's height represented the scaled standard deviation for the AC-CE axis, while the width represents the same for the AE-RO axis.

\section{Key findings}

The key findings of our analysis split according to our two research questions. The first categorizes, in accordance with ELT, the types of training programmes employed by aid organizations in the aftermath of Typhoon Haiyan. We analysed training programmes based upon their objectives and methods employed within the community from the qualitative analysis of the interviews with aid organizations and community members, triangulating the results with training materials collected on the ground. These findings first explore the similarities of overall objectives for training programmes and then account for the frequency of applied training methods, coded against Kolb's learning 
modes. Secondly, we present the individual and aggregated community learning style preferences resulting from administering Kolb's LSI within the selected communities.

\section{Training objectives}

It is widely noted in the literature that setting training objectives aid significantly in effective knowledge transfer (Kraiger et al., 1995; Lee and Pucel, 1998; Kontoghiorghes, 2001; McCrudden and Schraw, 2007). Optimally, a training programme's design should start with needs assessment to determine: organizational goals, where training is needed, and a robust analysis of the training audience in order to determine their learning needs and preferences (Arthur et al. 2003). This process establishes the evaluation criteria needed to conduct an evaluation of how the training programme performed on its intended function. The effectiveness of the training programme conveys itself through a specific measure of the intended changes to an individual's skill or behaviour. Through the coding process, we found specific references to stated objectives of the three organizations leading shelter projects in the selected communities. Our findings discuss the training objective similarities that all of the organizations emphasized and shared in their interviews. All three organizations studied discussed two distinct training programmes within each community - one geared towards the builders of post-disaster shelters and the other centred on training the individual homeowners.

\section{Builder-centric}

For the builder-centric training programme, the method of training relied heavily on certification standards from the Filipino government agency known as the Technical Education and Skill Development Authority (TESDA). Enacted in 1994, TESDA's overall purpose is to 'promote and strengthen the quality of technical education and skills development programmes to attain international competitiveness' (de Venecia and Angara, 1994, p. 2). Within this programme, middle-level skilled workers, including carpenters and masons, undergo a structured programme that concludes with a certification if trainees meet certain prescribed competency standards. While TESDA's training programme does not specifically target post-disaster shelter construction, the certification process remained a highly coveted asset to both aid organizations and shelter beneficiaries who sought to employ builders in disaster-affected areas. All references, no matter the source, spoke positively of having TESDA trained and certified builders. One of the organization's team leaders instructed shelter beneficiaries, 'It's more practical to hire the builders that were trained by TESDA' and that 'before we started the construction of houses, we have this training with TESDA. The builders and those who were interested attended the training.' Although certification was not a requirement to work on building shelters, organizations encouraged community members to hire a trained and certified builder. The Director of Education for an organization described complementary characteristics for builders in that 'they are the people with the construction experience, they are the builders, they are the people from inside the community, the people that we have worked with before, very familiar with our systems, the best people to train'.

On top of their TESDA training and prior work experience, skilled builders received additional training from aid organizations on specific construction plans for designed structures. In terms of ELT, an initial lecture-based review of blueprints and technical documents allowed builders to grasp the new design through the lens of the abstract conceptualization mode. The Education Director reinforced the reliance on the document review, by saying, 'We use the construction documents as the main point of reference for everything. So for all training, there is always the relationship to the construction documents.' Experienced builders progressed through the ELT cycle by moving out of the classroom, typically to the construction of a 'pilot' house that transformed the grasped construction concepts via active experimentation. When asking an organization's shelter consultant if this step helped assess the builder's knowledge, he responded, 'Yeah, by doing rather than having all these theoretical ways to do it.'

\section{Homeowner-centric}

Whereas the builder received technical instruction on specific construction methods from TESDA, aid organizations indicated that homeowners needed broader and less technical training. A shelter cluster coordinator stated, 'We train all the beneficiaries at recovery but the expectation isn't that they will be able to build a house for themselves after this training but rather that they are aware of the key messages.' The key messages he mentions refer to the 'Build Back Better' initiative found with the UN's Sendai Framework. In essence, the UN's success criterion was to raise awareness of these key messages within communities so that they could better understand the intent of better building practices. Building on this objective theme, the shelter consultant conveyed the importance that raising homeowner awareness of sustainable construction methods is paramount to resiliency by saying, 'we developed the methodology, we don't do anything, people will have to do it, [and] we can facilitate and train them to do 
it.' He continues by saying a key aspect of their training programme is that 'people can do it [learn] so they can train each other, others can't do it but they can help each other... and that is resilience'.

A second stated objective for homeowners was to train them on how to effectively screen and hire competent builders for their homes. An organization's area team leader described that once they identified a beneficiary for a new shelter, 'before you [beneficiary] will be given this project, you have to go through first with the homeowners training, to ensure that you can find a builder who will pass the builder's screening'. The team leader continued that once a homeowner hires a builder, any subsequent decisions and agreements made (e.g. material purchases) are between them and do not involve the aid organizations. Therefore, the aid organizations deemed builder screening a particularly essential skill to train.

A last collective objective for homeowner training found among the aid organizations was that homeowners needed to know how to procure good, quality materials for building their homes. It is an important aspect as noted by the Director of Education when he said, 'material quality is included in this training, for [the] homeowner is responsible for that.' An architect from one of the aid organizations reiterates this point when he said

We explain to them that you will be living in this house so you must know how to choose materials. We usually had training with our consultant engineer and we trained homeowners... how to choose materials that are safe to use in the construction.

To summarize, the training objectives set forth by the aid organizations were different for builders and homeowners. The builders, preferably TESDA certified, received technical instruction on how to build the designed shelter by focusing on the provided plans and practical experience on a pilothouse. For homeowners, aid organizations wanted to raise their awareness of resilient building practices, how to screen capable builders properly for hire, and how to procure safe and reliable building materials.

\section{Training methods}

The coding process revealed two distinct attributes of the employed training programmes. The first attribute relates to the interviewees' occupation. This ranged from fishermen or unemployed beneficiaries (titled 'homeowner') to individuals that had construction experience who also participated in the shelter building process (titled 'builder'). There were a few cases where these overlapped, such as a fisherman who also actively participated in construction, so they coded as 'mix'. The second attribute classified the training programme's delivery method into the four Kolb learning modes. For instance, when a community member spoke of attending a seminar presentation regarding construction methods and processes, but it lacked any participatory activities, this interaction coded as solely within the reflective observation mode. Table 2 lists the percentage of community members, separated by the aforementioned occupation type, which received training in a manner tied to one of the ELT modes. It is worth noting that 27 of the 28 interviewees received training that classify as reflective observation and members from Cantahay experienced the widest variety of ELT modes.

Further analysis linked these training methods with the training objectives and intended audience. For example, a builder from Cantahay first received an extensive plan overview (AC) and a lecture that included 'how to do the construction work, like how to do the flooring, the footing, the posts, and the like' (RO). When asked to elaborate, the builder stated the lecture was 'just for half a day only, and it was done one morning; in the afternoon we proceeded with the actual house construction'. Therefore, aid organizations rounded out a builder's skill set through additional training on a 'pilot' house with the aid of a supervising engineer (AE, CE). The Director of Education explained,

You can look at a construction plan, but you can't visualize in your mind what it looks like. So, being able to have these completed structures, and being able to do this training in that kind of environment really helps them to build.

Table 2. Relative frequency by ELT mode.

\begin{tabular}{|c|c|c|c|c|c|c|c|c|c|c|}
\hline \multirow[b]{2}{*}{ Cantahay } & \multirow[b]{2}{*}{ Homeowner } & \multirow{2}{*}{$\begin{array}{c}\text { Total respondents } \\
5\end{array}$} & \multicolumn{2}{|c|}{ AC (thinking) } & \multicolumn{2}{|c|}{$\mathrm{AE}$ (doing) } & \multicolumn{2}{|c|}{ CE (experiencing) } & \multicolumn{2}{|c|}{ RO (reflecting) } \\
\hline & & & $0 \%$ & (0) & $20 \%$ & (1) & $40 \%$ & (2) & $100 \%$ & (5) \\
\hline & Builder & 0 & $0 \%$ & (0) & $0 \%$ & (0) & $0 \%$ & (0) & $0 \%$ & (0) \\
\hline & Mix & 3 & $33 \%$ & (1) & $67 \%$ & (2) & $67 \%$ & (2) & $100 \%$ & (3) \\
\hline \multirow[t]{3}{*}{ Cogon } & Homeowner & 6 & $0 \%$ & (0) & $0 \%$ & (0) & $17 \%$ & (1) & $100 \%$ & (6) \\
\hline & Builder & 1 & $0 \%$ & (0) & $100 \%$ & (1) & $0 \%$ & (0) & $100 \%$ & (1) \\
\hline & Mix & 0 & $0 \%$ & (0) & $0 \%$ & (0) & $0 \%$ & (0) & $0 \%$ & (0) \\
\hline \multirow[t]{3}{*}{ Sulangan } & Homeowner & 10 & $0 \%$ & (0) & $20 \%$ & (2) & $40 \%$ & (4) & $100 \%$ & (10) \\
\hline & Builder & 1 & $100 \%$ & (1) & $0 \%$ & (0) & $0 \%$ & (0) & $0 \%$ & (0) \\
\hline & Mix & 2 & $0 \%$ & (0) & $0 \%$ & (0) & $50 \%$ & (1) & $100 \%$ & (2) \\
\hline
\end{tabular}


The combination of all the ELT modes sufficiently provided these builders with the necessary skills to build a reliable structure according to the design drawings.

In contrast, the homeowners experienced vastly different methods of training. The first exposure that homeowners faced occurred during an early coordination meeting hosted by the aid organizations. As a part of this meeting, they presented technical blueprints and photographs of shelters in various stages of construction to future homeowners as a technique, aligning with reflective observation. A Sulangan beneficiary, when asked if they received an explanation regarding the new shelter design specifications, responded that, 'They just asked us to give it to the carpenters for them to follow.'

Additionally, the aid organizations across the three communities used these communal lectures to present information that included topics on construction, material purchasing, and preparation tactics. However, there remained a significant absence to any subsequent organizational training that would have satisfied the other ELT modes. Although, it emerged that beneficiaries often sought learning opportunities from within the $\mathrm{AE}$ and $\mathrm{CE}$ modes through informally observing the builders constructing their house. One respondent, with no construction experience, noted, 'Since they were already skilled carpenters and had undergone training, I got to learn from them.' These impromptu lessons covered complex topics such as blueprint interpretation to practical construction skills such as measurements, nailing, bracing, joints, and foundations.

\section{Community preferred learning style}

Using the aggregation method described in the quantitative analysis subsection, Figure 2 displays the three communities, consisting of mean averages for each continuum, plotted on the respective axis, along with standard deviations, shown as heights and widths of ovals. For further clarification, Table 3 contains the raw data for the respective community plots. Of note, the Learning Style Type Grid does not follow the standard coordinate plane format. In contrast, the values are reversed in terms of position on each axis. Additionally, the axes do not converge at zero, but instead the AE-RO dimension crosses at +6 , whereas the AC-CE axis crosses at +7 .

As Figure 2 depicts, along the prehension continuum (AC-CE), there remains a varied preference on how communities prefer to grasp new experience. While a majority of community respondents prefer concrete experience, there is a slight partiality for using abstract conceptualization to think about new concepts. The respondents, on the transformation continuum (AE-RO), gravitate toward the reflective observation mode over active experimentation, which speaks to how respondents prefer to transform these grasped

Table 3. Learning style inventory means and standard deviations.

\begin{tabular}{lcccc}
\hline Barangay & $\begin{array}{c}\text { Avg } \\
\text { AE-RO }\end{array}$ & $\begin{array}{c}\text { Avg } \\
\text { AC-CE }\end{array}$ & $\begin{array}{c}\text { Std Dev } \\
\text { AC-CE (H) }\end{array}$ & $\begin{array}{c}\text { Std Dev } \\
\text { AE-RO (W) }\end{array}$ \\
\hline Cantahay & -7.7 & 1.9 & 8.1 & 5.9 \\
Cogon & -2.8 & 6.4 & 5.7 & 4.5 \\
Sulangan & -1.7 & 3.5 & 6.8 & 3.8 \\
OVERALL & -4 & 3.9 & 6.9 & 4.7 \\
\hline
\end{tabular}

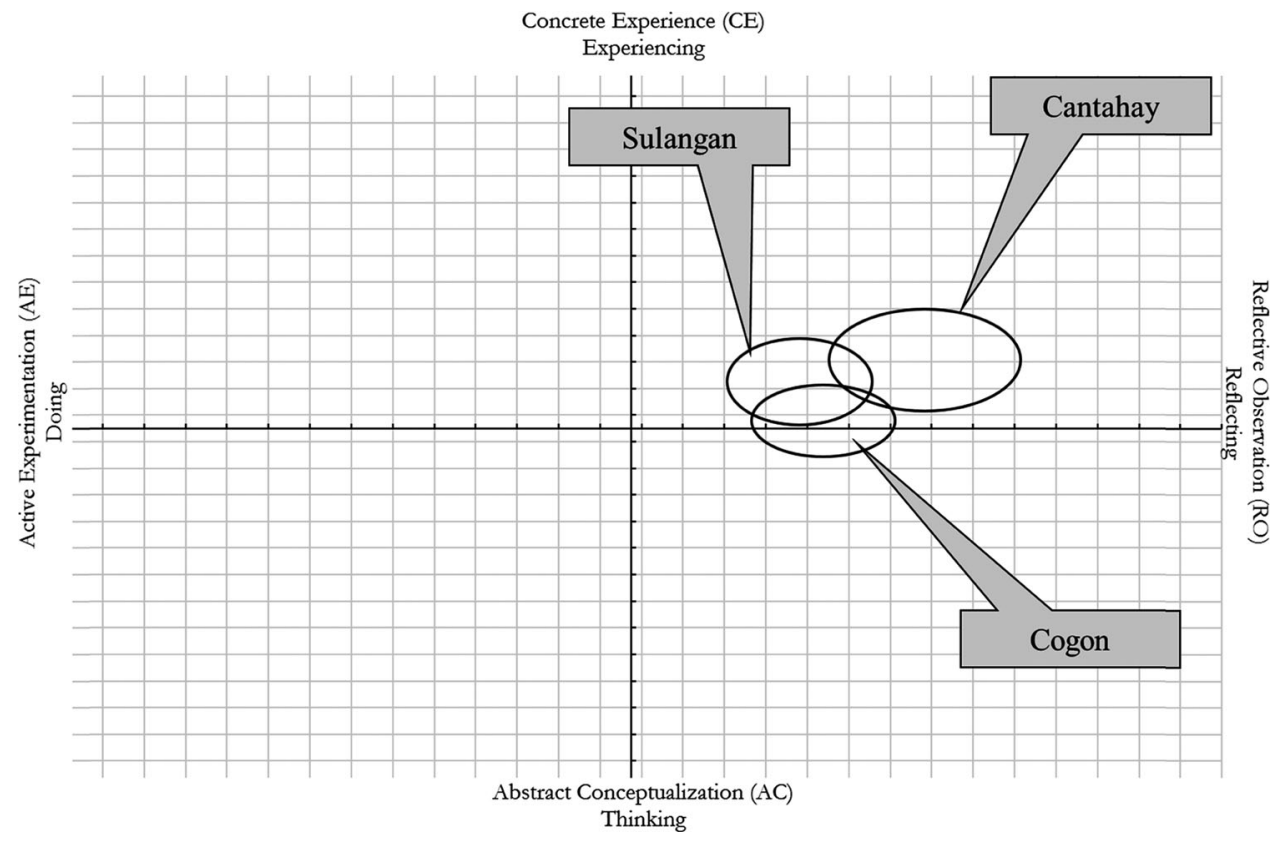

Figure 2. Community learning style inventory. 
experiences. Across all three communities, therefore, the preferred learning style is primarily diverging, but teeters close to the assimilating style.

Kolb submits the greatest strength of the divergent learning style lies in using 'imaginative ability' to gather 'many perspectives' in a manner that is best suited for the 'generation of alternative ideas and implications' (1984, pp. 77-78). Alternatively, the assimilator relies on 'inductive reasoning' to incorporate 'disparate observations into an integrated explanation' (Kolb, 1984, p. 78). While the choice for a lecture-based format suited the emphasis on reflection rather than active experimentation, aid organizations fell short when addressing the need to process newly acquired information. These two descriptions are apt in explaining the importance of alignment in terms of a community's preferred learning style and that of an aid organization's approach to teaching sound construction principles.

\section{Discussion}

Kolb's ELT is rooted deeply in the learning process, wherein a learner progresses through the cycle of learning modes (CE, RO, AC, $\mathrm{AE}$ ) to gain true knowledge of a given subject. The relative emphasis of how a learner grasps (abstract vs. concrete) then transforms (active vs. reflective) experience into knowledge is defined by Kolb into four learning styles (convergent, divergent, assimilate, accommodate). While Kolb highlights the importance of progressing through the learning modes and by default, the learning styles, he accounts for the human tendency to form habits and preferences that stem from experience, skill, and attitude. It should be concluded, therefore, that an effective learning programme first acknowledges a learner's preference, but then purposefully addresses the remaining gaps to complete the cycle of experiential learning.

Through analysis of training programmes and learning modes, we noted two distinct findings regarding the types of post-disaster training administered: (1) those that actively participated in the construction of new shelters (skilled workers or those with construction experience) received a wider exposure to each of the learning modes and (2) unskilled homeowners received formal training predominately through lecture (RO), but actively sought out informal experience through observing the construction process (CE).

Builders, therefore, had greater coverage of the ELT cycle, through detailed plan reviews, demonstrations on pilot shelters, and active construction work. The broad exposure of multiple modes, coupled with relying on the process of experiential learning, pushes these builders into a more complex form of development. Kolb calls this a 'shift in the frame of reference used to experience life, evaluate activities, and make choices' that results in an 'increasing experience of self as process' (1984, p. 210, emphasis in the original). In other words, skilled builders trained in this manner gain control of their interactions with the environment by better integrating the techniques of the four modes in increasingly complex scenarios. Instead of merely giving the answer, they are equipped with the process to finding their own answer.

Conversely, aid organizations had a tendency to employ fewer of the learning modes for homeowners, mainly providing lecture-based seminars. By only providing one mode of learning, this form of training did not accommodate all learning styles, nor did it emphasize various aspects of the learning cycle as prescribed by ELT. While lectures accurately aligned with the community preference toward grasping new experiences, aid organizations fell short when providing learning opportunities for processing the presented concepts. Active demonstration or practical exercises that incorporate construction work would have adequately addressed this gap in the learning process.

The practicality of administering a construction training programme to entire communities that also adheres to the entire process expounded by ELT has its restrictions. Limited resources in the form of finances, materials, time, and participation hamper the ability of aid organizations to teach in a comprehensive way. Yet, our exploratory research suggests that focusing the resources on the builders, and training the builders to educate the community members, may offer the best opportunity to offer post-disaster training to the community. With this, we suggest that aid organizations could maintain the processional learning (lecture, model house demonstrations, actual construction work), but add a 'train-the-trainer' programme to the curriculum that empowers builders to teach relevant construction knowledge to housing beneficiaries during construction. This will concentrate scarce resources to targeted audiences (builders) who can then multiply the impact of the training without burdening already taxed aide organizations.

\section{Limitations and future work}

We acknowledge several limitations in the LSI. For instance, there is little empirical evidence that shows the predicative ability of the LSI results towards an individual's performance in knowledge transfer, understanding, and application (Koob and Funk, 2002; Manolis et al. 2013). Furthermore, Kolb claims that learners need to learn immersed within all four learning styles, yet his LSI ipsative rating scale forces respondents to 
narrowly choose between the four statements (Henson and Hwang, 2002; Kayes, 2005). There is also no room for flexibility or comparative analysis (i.e. it is impossible to score as strong or weak in all four styles), and, by identifying a single preferred style, it makes it impossible to identify relevant substyles (Manolis et al. 2013). However, we believe that analysing the predominant learning style within a community, and comparing this to the learning modes that existing training programmes accommodate, offers new insights that will help improve post-disaster training programmes. Specifically, we hypothesize that if an aid organization, set to teach a community better construction practice, customizes their teaching methods to accurately fit the dominate learning styles of the target audience, the retention and application of the new knowledge will improve. This may result in stronger civil infrastructure construction, thus increasing resiliency within the community.

This leads us to recommendations for future work. Specifically, we encourage work that will administer construction knowledge examinations that test respondent's understanding and retention of the UN's 'Build Back Better' themes. Administering this test, and comparing test results to the learning modes of training programmes, will help future work determine the effectiveness of training programmes. Furthermore, additional research could conduct a longitudinal study to determine if achieving learning objectives changes behaviours in regard to construction and maintenance of resilient and sustainable infrastructure systems. Moreover, future work could analyse the root causes for differences in knowledge retention and application by community members, be it the impact of learning style within different cultures and contexts, specific demographic variables, or a multitude of overlapping characteristics that emerge.

\section{Conclusion}

We analysed the learning modes provided in post-disaster construction training programmes, bridging the disconnect in literature between disaster, educational and organizational theories. Much of existing knowledge in the project organization community that crosses these boundaries stems from studies at the national level (e.g. Chinowsky et al. 2011; Tsai and Chi, 2011). Our findings provide new insights that connect programme and individual attributes. Further, while educational research has traditionally focused on formal academic institutions (e.g. Skipper and Brandenburg, 2013), our analysis investigates technical skills development in field construction. Through the application of Kolb's ELT, we applied one educational theory into a previously under-represented domain (disasters). In this light, we have categorized the training programmes administered by organizations recovery efforts following Typhoon Haiyan according to Kolb's ELT.

Our analysis shows that builders had greater exposure to the full cycle of ELT modes, not only from organizational training programmes, but also through past construction work and the TESDA formalized certification programme. For the case of homeowners, this group predominately received structured training in the form of seminars and lectures that we solely linked to the RO mode. However, as the LSI results convey, the three communities tend to gravitate toward $\mathrm{RO}$ instructional methods when grasping new experiences. Yet, as Kolb describes, 'more powerful and adaptive forms of learning emerge when these strategies [learning styles] are used in combination' (1984, p. 65). Intuitively, homeowners sought out additional learning opportunities outside the organized classroom that crossed the $\mathrm{AE}$ and $\mathrm{CE}$ modes by observing the construction of their new shelter. By watching, or even participating in the construction process, they transformed their conceptual knowledge into applicable skills.

Practically, aid organizations should promote the additional role of skilled builders as educators for unskilled homeowners during actual construction. This inclusion of builders as trainers promotes efficient use of scarce funding while maximizing inclusion of homeowner oversight in construction. By focusing on a select audience of experienced skilled builders and establishing training objectives grounded in ELT, training programmes can increase the resilience of communities and infrastructure.

\section{Acknowledgements}

This research would not have been possible without the assistance and support of our competent research assistants, Marielle Bacason, Lebeth Manguilimotan, and Phoebe Tabo. Additionally, Ursula Grunewald, who assisted with qualitative coding and coding validation within QSR NVivo. The authors would also like to thank the Hay Group who graciously permitted the use of the Kolb LSI questionnaire for the learning style assessment.

\section{Disclosure statement}

No potential conflict of interest was reported by the authors.

\section{Funding}

This material is based upon work supported by the National Science Foundation [under grant number 1434791]. Any opinions, findings, and conclusions or recommendations expressed in this material are those of the author(s) and do not necessarily reflect the views of the National Science Foundation. 


\section{ORCID}

Alexander Zerio (1D) http://orcid.org/0000-0002-8175-5389

Aaron Opdyke (D) http://orcid.org/0000-0003-1507-6270

Amy Javernick-Will (D) http://orcid.org/0000-0002-3933-2614

\section{References}

Arthur, W.Jr., Bennett, W.Jr., Edens, P.S. and Bell, S.T. (2003) Effectiveness of training in organizations: a meta-analysis of design and evaluation features. Journal of Applied Psychology, 88(2), 234-45.

Asharose, Saizen, I. and Sasi, P. (2015) Awareness workshop as an effective tool and approach for education in disaster risk reduction: a case study from Tamil Nadu, India. Sustainability, 7(7), 8965-84.

Barakat, S. (2003) Housing Reconstruction after Conflict and Disaster, Overseas Development Institute, London.

Barenstein, J.D. (2006) Housing Reconstruction in PostEarthquake Gujarat: A Comparative Analysis. Humanitarian Practice Network, Overseas Development Institute, London.

Barmeyer, C.I. (2004) Learning styles and their impact on cross-cultural training: an international comparison in France, Germany and Quebec. International Journal of Intercultural Relations, 28(6), 577-94.

Chinowsky, P., Hayles, C., Schweikert, A., Strzepek, N., Strzepek, K. and Schlosser, C.A. (2011) Climate change: comparative impact on developing and developed countries. Engineering Project Organization Journal, 1(1), 67-80.

Creswell, J.W. (2013) Research Design: Qualitative, Quantitative, and Mixed-Method Approaches, Sage, Los Angeles.

Davidson, C.H., Johnson, C., Lizarralde, G., Dikmen, N. and Sliwinski, A. (2007) Truths and myths about community participation in post-disaster housing projects. Habitat International, 31(1), 100-115.

Del Rosario, E. (2014) Effects of Typhoon Haiyan. Nation Disaster Risk Reduction and Management Council.

Dewey, J. (1938) Experience and Education. Kappa Delta Pi, West Lafayette.

Fallahi, A. (2007) Lessons learned from the housing reconstruction following the Bam earthquake in Iran. The Australian Journal of Emergency Management, 22(1), 26-35.

Fereday, J. and Muir-Cochrane, E. (2006) Demonstrating rigor using thematic analysis: a hybrid approach of inductive and deductive coding and theme development. International Journal of Qualitative Methods, 5(1), 80-92.

Grochow, J. (1973) Cognitive style as a factor in the design of interactive decision-support systems, $\mathrm{PhD}$ dissertation, Massachusetts Institute of Technology, Sloan School of Management.

Guha-Sapir, D., Hoyois, P. and Below, R. (2015) Annual Disaster Statistical Review: Numbers and Trends 2014, Centre for Research on the Epidemiology of Disasters, Brussels, Belgium.

Henson, R.K. and Hwang, D.-Y. (2002) Variability and prediction of measurement error in Kolb's learning style inventory scores a reliability generalization study. Educational and Psychological Measurement, 62(4), 712-27.

Hofstede, G. (2001) Culture's Consequences: Comparing Values, Behaviors, Institutions, and Organizations Across Nations, Sage, Thousand Oaks, CA.
Hudson, L. (1966) Contrary Imaginations, Penguin Books, Middlesex.

ISDR. (2007) Hyogo Framework for Action 2005-2015: Building the Resilience of Nations and Communities to Disasters, UNISDR, Geneva.

Jha, A.K. (2010) Safer Homes, Stronger Communities: A Handbook for Reconstructing After Natural Disasters, The World Bank, Washington, DC.

Johnson, R.B., Onwuegbuzie, A.J. and Turner, L.A. (2007) Toward a definition of mixed methods research. Journal of Mixed Methods Research, 1(2), 112-33.

Joy, S. and Kolb, D.A. (2009) Are there cultural differences in learning style? International Journal of Intercultural Relations, 33(1), 69-85.

Kayes, D.C. (2005) Internal validity and reliability of Kolb's learning style inventory version 3 (1999). Journal of Business and Psychology, 20(2), 249-57.

Kolb, A.Y. and Kolb, D.A. (2005) The Kolb Learning Style Inventory-Version 3.12005 Technical Specifications, HayGroup, Boston, MA.

Kolb, D.A. (1984) Experiential Learning: Experience as the Source of Learning and Development, Prentice-Hall, Englewood Cliffs.

Kontoghiorghes, C. (2001) Factors affecting training effectiveness in the context of the introduction of new technology A US case study. International Journal of Training and Development, 5(4), 248-60.

Koob, J.J. and Funk, J. (2002) Kolb's learning style inventory: issues of reliability and validity. Research on Social Work Practice, 12(2), 293-308.

Kraiger, K., Salas, E. and Cannon-Bowers, J.A. (1995) Measuring knowledge organization as a method for assessing learning during training. Human Factors: The Journal of the Human Factors and Ergonomics Society, 37(4), 804-16.

Lawther, P.M. (2009) Community involvement in post disaster re-construction - case study of the British red cross Maldives recovery program. International Journal of Strategic Property Management, 13(2), 153-169.

Lee, K. and Pucel, D.J. (1998) The perceived impacts of supervisor reinforcement and learning objective importance on transfer of training. Performance Improvement Quarterly, 11(4), 51-61.

Lewin, K. (1951) Field Theory in Social Sciences, Harper \& Row, New York.

Lum, T. and Margesson, R. (2014) Typhoon Haiyan (Yolanda): US and International response to Philippines disaster. Current Politics and Economics of South, Southeastern, and Central Asia, 23(2), 209-46.

Manolis, C., Burns, D.J., Assudani, R. and Chinta, R. (2013) Assessing experiential learning styles: a methodological reconstruction and validation of the Kolb Learning Style Inventory. Learning and Individual Differences, 23, 44-52.

McCrudden, M.T. and Schraw, G. (2007) Relevance and goalfocusing in text processing. Educational Psychology Review, 19(2), 113-39.

Munoz, S.R. and Bangdiwala, S.I. (1997) Interpretation of Kappa and B statistics measures of agreement. Journal of Applied Statistics, 24(1), 105-12.

NEDA. (2013) Reconstruction Assistance on Yolanda, National Economic and Development Authority.

Olshansky, R.B. (2009) The challenges of planning for postdisaster recovery. Building Safer Communities: Risk 
Governance, Spatial Planning and Responses to Natural Hazards, 58, 175-81.

Piaget, J. (1973) To Understand is to Invent: The Future of Education, Grossman, New York.

Prince, M.J. and Felder, R.M. (2006) Inductive teaching and learning methods: definitions, comparisons, and research bases. Journal of Engineering Education, 95(2), 123-38.

Ruble, T.L. and Stout, D.E. (1990) Reliability, construct validity, and response set bias of the revised learning style inventory (LSI-1985). Educational and Psychological Measurement, 50(3), 619-29.

Ruble, T.L. and Stout, D.E. (1991) Reliability and classification stability, and response set bias of alternative forms of the learning style inventory (LSI-1985). Educational and Psychological Measurement, 51(2), 481-89.

Skipper, C.O. and Brandenburg, S. (2013) Emotional intelligence and academic performance of engineering students. Engineering Project Organization Journal, 3(1), 13-21.

Sullivan, M. (2003) Integrated recovery management: a new way of looking at a delicate process. Australian Journal of Emergency Management, 18(2), 4-27.

Thayaparan, M., Siriwardena, M., Malalgoda, C.I., Amaratunga, D., Lill, I. and Kaklauskas, A. (2015) Enhancing post-disaster reconstruction capacity through lifelong learning in higher education. Disaster Prevention and Management: An International Journal, 24(3), 338-54.
Thwala, W.D. (2005) Employment creation through the provision of low cost housing in South Africa, in Proceedings of the XXXIII IAHS World Congress on Housing: Transforming Housing Environments through Design, Pretoria, South Africa, pp. 27-30.

Torrealba, D. (1972) Convergent and divergent learning styles, Master's thesis, Massachusetts Institute of Technology, Sloan School of Management.

Tsai, J.-S. and Chi, C.S.F. (2011) Dysfunction of governmental emergency management system for natural disaster: a case study of Taiwan Xiaolin village. Engineering Project Organization Journal, 1(2), 107-19.

Tuladhar, G., Yatabe, R., Dahal, R.K. and Bhandary, N.P. (2015) Disaster risk reduction knowledge of local people in Nepal. Geoenvironmental Disasters, 2(1), 1-12.

UNISDR. (2015) Sendai Framework for Disaster Risk Reduction 2015-2030, Geneva, Switzerland, p. 37.

de Venecia, J. and Angara, E. (1994) Technical Educational and Skills Development Act of 1994, p. 22.

Veres, J.G., Sims, R.R. and Locklear, T.S. (1991) Improving the reliability of Kolb's revised learning style inventory. Educational and Psychological Measurement, 51, 143-50.

Yamazaki, Y. (2005) Learning styles and typologies of cultural differences: a theoretical and empirical comparison. International Journal of Intercultural Relations, 29(5), 521-48. 